\title{
Approaches for investigating university libraries as learning organisations
}

\author{
Saowapha Limwichitr, Judith Broady-Preston, David Ellis
}

\begin{abstract}
Presented in this paper are research approaches for investigating university libraries as Learning Organisations (LOs), developed in the context of Thai university libraries.

A Learning Organisation is one in which individuals "at all levels continuously learn and transform themselves, based on their experiences, with the purpose of enhancing their individual capacity, improving their routines, as well as developing organisational performance as a whole" (Limwichitr, 2016, p.18). In the context of university libraries, becoming an LO has the potential to reinforce their ability to remain relevant in a period of fundamental change in library and information service provision. Investigating the adoption of this concept within this context remains problematic due to the lack of a context-adapted approach for such an investigation.
\end{abstract}

\section{Authors}

Saowapha Limwichitr studied Librarianship at Aberystwyth University, UK and is a lecturer in the Department of Library Science, Chulalongkorn University, Thailand.

Email: $\underline{\text { Saowapha.1@ chula.ac.th }}$

Judith Broady-Preston is Professor of Information Management and Director, Institute of Professional Development, Aberystwyth University.

David Ellis is Professor of Information Studies and Director of Research in the Institute of Professional Development, Aberystwyth University.

Received 20 February 2017

Accepted 18 January 2018 
Outlined and discussed in this paper is such a contextual approach derived from a completed doctoral study in which the development of university libraries into learning organisations was examined, using universities in Thailand as case studies. A qualitative case study methodology was employed, using three methods of data collection: document analysis, semi-structured interviews, and observation to corroborate data in order to increase validity and credibility of the research findings. An interpretivist lens was chosen given the need to investigate how university libraries dealt with organisational transformation into LOs. The focus of this paper is on the lens, research approach, and methods employed in the study. The approach was successful in providing a context-based approach to investigating learning organisations, developed to suit the Thai context and culture. Factors to be considered in adopting the approach for further studies in other contexts were also identified and are discussed below.

\section{Introduction}

The concept of the learning organisation began to emerge in the 1970s, expanded and popularised subsequently by several commentators, such as Garvin (1993), Senge (1995), Pedler, Burgoyne and Boydell (1997), Marsick and Watkins (2003), and Marquardt (2011) amongst others. Based on the definitions proposed by key authors, the learning organisation is defined for this study as "an organisation where people at all levels continuously learn and transform themselves based on their experiences with the purpose of enhancing their 
individual capacity, improving their routines, as well as developing organisational performance as a whole" (Limwichitr, 2016, p.18). Viewed as a key tool in enhancing the ability of university libraries to adapt to rapid change through a process of continuous learning and service innovation, the concept emerged in a university library context in the late 1990s (Madge, 2013).

The main focus of a learning organisation is to ensure that learning and development are integral elements of organisational culture and practices; learning becomes rooted in an organisational context and culture, and embedded within staff work routines. The concept thus ensures their sustainable learning and growth.

Several themes emerge from the literature relating to the development of learning organisations in the university library context, centred on the need to:

- clarify the concept in a university library context

- identify the characteristics of a learning organisation

- provide practical strategies to transform existing university libraries into learning organisations (Limwichitr, Broady-Preston \& Ellis, 2015).

The latter issue is viewed as especially problematic.

Three major difficulties in investigating the topic have been reported repeatedly in the literature, namely: (1) a lack of consensus with regard to meaning; (2) little or no practical guidelines for implementing the concept; and (3) few approaches for measuring and evaluating the success of a learning organisation (Garvin, 1993; Grieves, 2008; Kitt, 2008). 
These three difficulties correspond with the three problematic aspects relating to Meaning, Management, and Measurement identified in the Garvin Three Ms Framework (Garvin, 1993). University libraries therefore are required to develop an understanding of these three aspects in order to move towards becoming true learning organisations.

Further difficulties in developing the concept result from the need to identify the critical success factors facilitating or inhibiting learning within the existing organisational culture (Marquardt, 2011). These factors need to be taken into account throughout the stages of investigation in order to identify and remove barriers to organisational transformation. There is also a need for a contingency or a context-adapted approach, customised to fit differing types of organisations, encompassing their context and culture (Örtenblad, 2015). Örtenblad contends that the concept of the learning organisation has been promoted as "a panacea that all organisations, regardless of context must adopt" $(2015$, p. 163), resulting in the view of it being universally applicable as a 'one size fits all' approach without any modifications. He argues that each organisation requires its own unique approach to establishing itself as a learning organisation. A critical challenge was thus to seek a new approach which integrated these aspects.

As outlined above, presented in this paper are research approaches for investigating university libraries as learning organisations based on aspects of a completed doctoral study (Limwichitr, 2016). The aim of the original study was to investigate the development of 
university libraries into learning organisations, using and adapting the Garvin Three Ms Framework, viz:

- Meaning: examining how the notion of a learning organisation and its meaning has been constructed and perceived within university libraries.

- Management: identifying managerial practices and the extent to which they support building a learning organisation.

- Measurement: assessing whether current practices of the university libraries are compliant with the notion of a learning organisation.

A case study approach using Thai university libraries addressed the importance of developing a context-based approach. In Thailand, the requirement to become a learning organisation is compulsory for university libraries, as outlined in and governed by National Governmental law, rules, and regulations (further discussed below). Therefore, this study sought to understand the extent to which university libraries in Thailand have transformed their practices in response to such government-led initiatives.

The research methodology employed in the doctoral study is the focus of this paper. The background to the study is presented in the following paragraphs, outlining the rationale for investigating learning organisations, together with an overview of the implementation of the concept in Thai university libraries. The qualitative case study approach is then presented, including details of the case study conduct and analysis. Reflection on the research approaches is discussed in the final section. 


\section{Investigating a learning organisation}

Transforming themselves into learning organisations enables university libraries to learn from and adapt to changes in the twenty-first century, particularly in relation to technological innovation and financial challenges. The migration from paper to electronic resources has resulted in changing roles for librarians, from custodians to information intermediaries with a decline in visibility to the library service end users (Creaser \& Spezi, 2012). To remain relevant in such a changing environment university libraries need to realign and adapt by building up capacity and creating service innovations in response to user needs (Mullins and Christy, 2016).

Arguably, by becoming learning organisations, libraries are better equipped to survive and thrive in the continuously changing information environment. With this focus on continuous improvement at the individual level, its staff are encouraged to improve their skills, and supported to learn and develop as individuals thereby providing more opportunities for progression and movement within the organsiation (Giesecke \& McNeil, 2004). From an organisational perspective, libraries benefit significantly through continuous learning, improvement and innovation as well as increasing their strategic agility and flexibility resulting in overall improvements to organisational performance (Michael \& Higgins, 2002; Jain \& Mutula, 2008).

The early literature highlights the need for libraries to adopt this approach to survive in a changing environment. The early theorists established basic theoretical principles, 
together with recommendations on how to apply these in a university library context (Worrell, 1995; Rowley, 1997; Fowler, 1998). Whilst the concept became more widely known, the focus of the literature remained in identifying and discussing its characteristics, together with an examination of strategies or approaches for developing libraries into learning organisations. University libraries provided their staff with learning and development activities; organisational structures and work processes were simultaneously restructured for flexibility and to provide a better response to user needs (Michael \& Higgins, 2002; Giesecke \& McNeil, 2004; Jain \& Mutula, 2008; Madge, 2013).

Difficulties in translating the concept into practices may occur due to the unique characteristics of university library work processes and culture. Rigid departments and a high degree of task specialisation may potentially block or impede learning and development, especially if there is a history of autonomous working, resulting in a lack of knowledge sharing and collective learning across units (Bordeianu \& Lubas, 2013; Martin, 2013). Building a learning organisation entails not only executing policy and strategies relating to learning and development, but also modifying organisational systems supporting the provision of a learning organisation, such as organisational structure, culture, and leadership (McHugh, Groves, \& Alker, 1998).

The problematic aspects surrounding successful transformation of university libraries into effective learning organisations identified earlier may be categorised using Garvin's Three Ms framework (Garvin, 1993) and in turn, used as a framework for investigating university libraries as learning organisations. 
Critical success factors (CSFs) were identified from the literature review, categorised as either facilitators or inhibitors to the successful implementation of a learning organisation.

The following five main groups of CSFs were identified from a multi-disciplinary analysis of relevant literature, including business and management, library and information science, and education (Hitt, 1995; Michael \& Higgins, 2002; Giesecke \& McNeil, 2004; Sudharatna, 2004; Jain \& Mutula, 2008; Marquardt, 2011):

- Organisational policy and strategies to support staff learning at all levels in addition to integrating learning into organisational working life.

- Leadership styles that support and encourage staff learning and development, with a focus on the need to change from autocratic and task-oriented to more participative, visionary, and inspirational styles.

- Flat organisational structures featuring fluid, unbounded structures with no divisional barriers, streamlined to maximise flexibility, team collaboration, and enable the flow of learning and knowledge sharing.

- Organisational context and culture aligned to support learning and development with an emphasis on learning valued and promoted throughout, the organisational environment, climate and culture. 
- Continuous Measurement and evaluation systems not stand-alone activities, undertaken continuously as a means to improve the quality of work practices, with libraries acting directly on the results.

\section{Thai context}

In the context of Thai universities and their libraries, the concept of learning organisation began to emerge in 2005. A key influence was the promulgation of the Royal Decree of Good Governance and Management in 2003, requiring government agencies to implement knowledge management to support the development of a knowledge-based society by transforming themselves into learning organisations (OPDC, 2003). Thai public and autonomous university libraries had to transform themselves into learning institutions to comply with this Royal Decree. The Office of the Public Sector Development Commission (OPDC) and the Office of the Higher Education Commission (OHEC) have designated standard criteria and key performance indicators to assess their compliance. Examples of standard criteria and indicators include:

- Indicator 2.4 "System for faculty and supporting personnel": universities and their libraries are required to establish a system for supporting staff development

- Indicator 7.2 "Institutional development towards becoming a learning institution": outlining a strategy for institutional development towards becoming learning institutions. 
Higher education institutions (HEIs) are required to devise appropriate quality assurance (QA) systems and mechanisms, including criteria and procedures to enhance, support, and develop educational quality, with standard criteria and indicators of the OPDC and OHEC included in their QA systems. HEIs are also required to conduct annual reviews and selfevaluations to monitor the quality of their practices to ensure they have achieved certain aspects of a learning organisation as specified by the standard criteria and indicators (Fri \& $\mathrm{Bi}, 2013)$.

The development of HEI libraries into learning organisations is seen as a transformational process rather than one of radical change. A major challenge faced by this study was to identify research methods and approaches suitable not only for an investigation of the implementation of a learning organisation and culture in the abstract, but one which also allowed for investigation of a specific context and culture that of Thailand.

\section{Conducting an organisational case study}

The investigation was conducted using two contrasting lenses: (1) positivist and (2) interpretivist. The main difference between the two perspectives relies on a central conundrum as to whether a learning organisation can be managed (Garavan, 1997) and lead to the selection of differing approaches for investigating the topic.

From a positivist perspective, a learning organisation is viewed as a tangible object, with its own tangible reality. Learning is thus an entity or an attribute that an organisation possesses, 
which can be designed, managed and changed by organisational leaders according to organisational goals and needs (Garavan, 1997; Bratton, 2010). Positivist studies focus on identifying influencing variables and measuring such variables to ensure that they are wellmaintained to produce a learning organisation (Mumford, 1995; Garavan, 1997; Mueller, 2012). Such studies adopt a quantitative approach; employing statistical testing such as correlation analysis to demonstrate a positive correlation between the correct organisational culture to achieve a learning organisation and performance.

Interpretivist studies are based on a root metaphor or cultural perspective which considers a learning organisation as a metaphor and basically views the organisation itself as a type of culture - a learning culture (Garavan, 1997; Parding \& Abrahamsson, 2010).

Through an interpretivist lens, learning must be rooted within the organisation.

Transformation into a learning organisation requires an understanding of how the webs of meaning surrounding the concept are continuously constructed and reproduced by staff (Garavan, 1997; Mueller, 2012). A fundamental change in staff values and assumptions towards learning is required to change staff behaviour and working practices in order to establish an effective learning organisation. Interpretivist studies adopt a qualitative approach to exploring organisations as subjective entities, based on the view that a learning culture is "continuously constructed in ongoing interaction of people and reproduced by a network of symbols and meanings that unite people and make shared learning possible" (Garavan, 1997, p. 20). 
The study adopted an interpretivist lens to understand how university libraries dealt with organisational transformation when implementing the concept, examining how Meaning, the first 'M' of Garvin's 3M framework, was established and perceived. An organisation needs to understand its own organisational culture through a root metaphor lens to ensure that it encompasses an appropriate sense-making mechanism facilitating the adoption of the learning organisation construct. Thus, a learning culture plays a critical role in and becomes a mechanism for guiding and shaping staff values, perception, attitude, and behaviour.

Additionally, an attempt was made to employ this in conjunction with a positivist approach, viewing the learning organisation as an entity consisting of variables or CSFs that an organisation needed to develop and maintain (Garvin, 1993). Whilst an understanding of the development of a learning culture was attempted, this took place together with an examination of the interrelationship between the CSFs, focusing on identifying how these factors had been developed through the use of a qualitative approach to inquiry.

A qualitative case study approach was employed as the approach suits a study which needs to investigate how and why questions about "a contemporary phenomenon within its real-life context especially when the boundaries between phenomenon and context are not clearly evident" (Yin, 2014, p. 13) thereby offering a holistic and rich understanding of phenomena in a real-life setting. 
Case studies may be either a single or a multiple-case design depending on the purpose of the study (Yin, 2014). A single case design is appropriate to examine one significant in-depth case study which is a rare, unique or unusual case to gain "rich and deep understanding of the subject and breakthrough insights" (Patton, 2015, p. 266). This study used a multiple case design as the purpose was not only to understand the phenomenon of developing a learning organisation but also to confirm emerging constructs through the research findings derived from multiple case libraries. Multiple case evidence is more compelling and can provide stronger arguments in relation to study validity (Shakir, 2002; Farquhar, 2012; Yin, 2014; Patton, 2015).

There are two main strategies for case selection: random selection and informationoriented selection (Flyvbjerg, 2006). Purposive sampling was used; cases were selected as information-rich and on the basis of their potential contribution to theory development (Ritchie, 2003). The university libraries were selected using three predetermined criteria library size, age of the library, and library interest.

- Library size has a direct effect on how an organisation is structured to facilitate learning in organisations. In small university libraries, management is relatively straightforward. As organisations grow, they often begin to formalise their management practices by launching formal strategic plans to support learning and development, developing their communication channels to involve staff in decision-making, and investing in formal training programmes to meet current and future skills needs. 
In Thailand, the size of university libraries is based on the number of library holdings, staff and budget for carrying out collection management. For this study, libraries were grouped by size as follows:

- small libraries $<50$ staff

- medium libraries $=50-100$ staff

$-\quad$ large libraries $=100-150$ staff

Large libraries were selected for this research as these libraries have a significant proportion of professional staff; a high level of cooperation amongst themselves; receive substantial budgets for staff development; together with networks to enhance learning, all of which should contribute to their ability to build a learning organisation.

- Library age relates to the libraries' ability to transform into learning organisations given their inherent traditions, organisational culture, or stable relationships that have been accumulated over time (Sudharatna, 2004; Figueroa \& González, 2006). Whilst library age may be a barrier to organisational change with older organisations possibly more restrictive, conversely they may also exhibit greater potential for strategic change having had more experience in dealing with and implementing such change (Su, 2009). The first university libraries in Thailand were established in 1915. Universities founded between 1915 and 1965 were selected, being both more established and possessing greater experience in facing pressure and adapting to change, including the case of developing as learning organisations. 
- Library interest criterion seeks to identify university libraries which have a story to tell. They should aspire to or show an active interest in building a learning organisation by including the learning organisation concept in their policy and strategies. These libraries may implement knowledge management practices continually or invest in human resource development. Their active interest was identified from screening information provided on the library websites such as their vision and mission statements. In some cases, the libraries had provided annual reports on their websites which could be used as a starting point for case screening.

The number of cases in a multiple-case design may vary according to purpose as well as available time and resources. The number of cases selected is a trade-off between breadth and depth. Whilst a small sample size permits inquiry into selected issues in great depth, a larger sample size can be helpful in exploring the diversity of a phenomenon. According to Patton (2015), a smaller sample size of six to ten cases is reasonable to investigate phenomena which generate large amounts of data. There are 156 university libraries in Thailand, comprising 22 autonomous universities, 13 public universities, 38 Rajabhat Universities, nine Rajamangala Universities of Technology, and 74 Private universities. For this study, six case libraries were chosen from the 35 autonomous and public universities (central libraries only) as they were directly affected by governmental educational policies and legislative requirements to transform themselves into learning organisations. 
The case library directors were contacted two weeks prior to the fieldwork phase to provide information about the research project. This allowed the directors to raise questions, and to clarify the purpose and research methods of the study. Permission to carry out the research was then obtained from the directors.

\section{Selection of the research methods}

Investigating a learning organisation is considered complex as it relates to aspects of organisational culture. Data collection methods need to allow organisational culture to be deciphered. Portfelt (2006) cautions that there is always conflict between 'espoused culture' and 'culture in practice'. An organisation may value learning and aspire to be a learning organisation but the actual day-to-day practices may not be supportive of such aspirations; time and resources may not support learning or day-to-day work routines may be valued over learning and development. Researchers, therefore, cannot rely solely on a single method (Eberle \& Maeder, 2011). They cannot rely merely on what is reported in documents or staff views of learning culture expressed during interviews.

Patton (2015) proposes the use of method triangulation, following the principle in collecting data of the same phenomenon from multiple data collection techniques, aiming at developing convergent evidence as well as corroborating the same findings in order to strengthen the construct validity of the case study. This approach has been used in earlier similar investigations; in 1994 Jones investigated the development of a learning culture in 
two organisations using documentary evidence, in-depth interviews, observation of people, events, and departments, including participation in training events and activities (Jones, 1994). Temple (2006) examined the development and implementation of a knowledge management strategy in a multi-cultural engineering design environment using interviews, observation, documentary analysis and access to data archives within the Nissan Company. In the LIS field, Mavodza (2010) investigated knowledge management practices in an academic library using document reviews, interviews, and observation to examine the changing role of the academic library in response to the changing environment.

In this research, three primary methods were used: document analysis, interview, and observation. These three methods reflect a more probing approach and are appropriate to acquiring an in-depth understanding of issues related to organisational culture (Creswell, 2013). The methods help researchers make better inferences about the actuality of the organisational culture as well as allowing a broader range of historical, contextual, and behavioural issues to be addressed with converging results, thereby establishing construct validity (Yin, 2014).

The three methods employed were complementary to each other. Documentary evidence was used as a starting point prior to fieldwork to obtain background and familiarise the researcher with the research fields. During the fieldwork, more internal documentary evidence was analysed and served as a guideline for conducting interviews with the library directors. Observation was undertaken throughout the fieldwork to gain an understanding of 
the learning environment, staff behaviour and interaction in learning activities. Figure 1 below outlines this process.

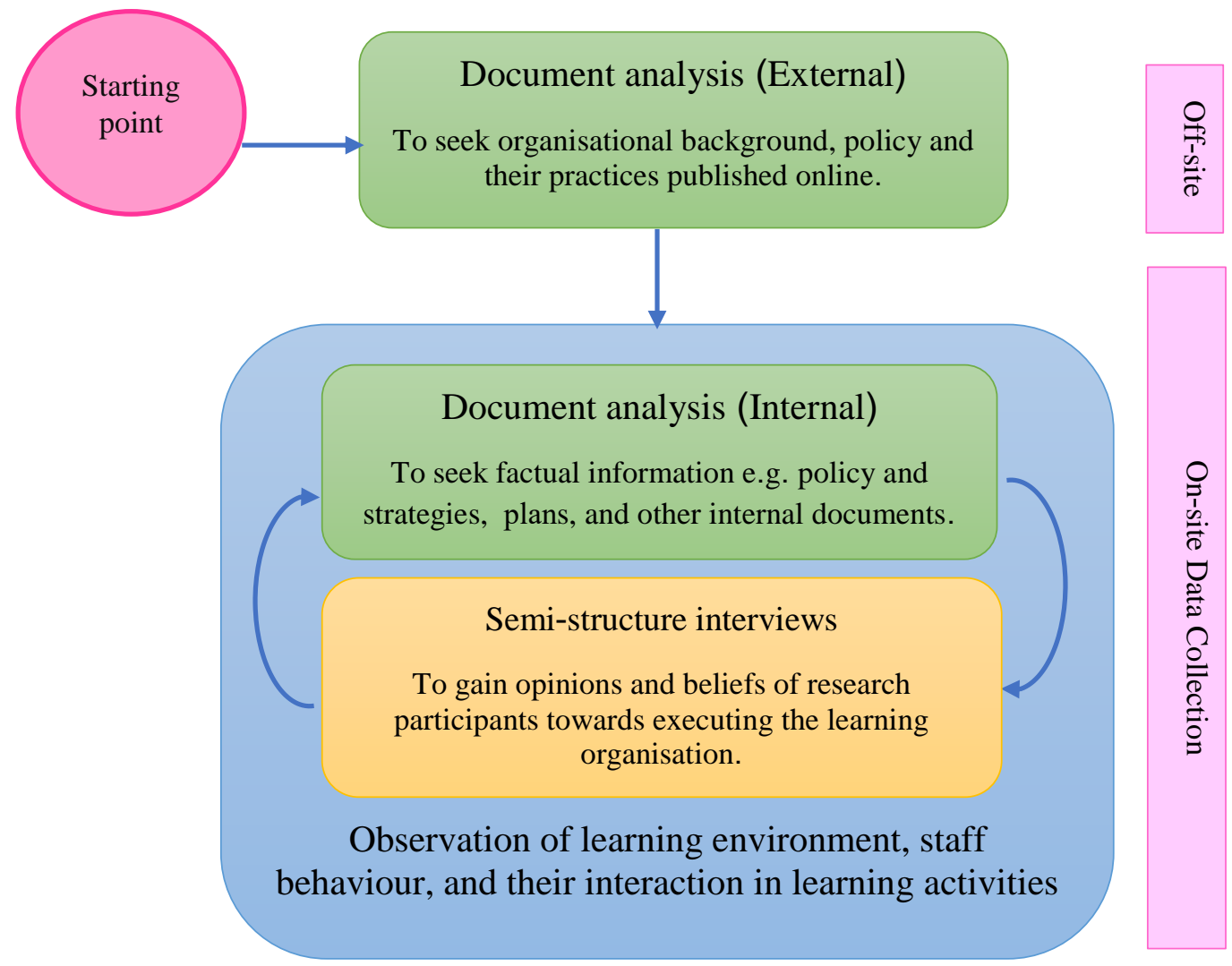

Figure 1: Research methods and their sequence 


\section{Document analysis}

Document analysis is a systematic process of searching and analysing relevant documents which can either be public documents such as annual reports, procedural documents, or internal documents such as organisational policy, minutes of meetings, or organisational bulletins circulated within an organisation (Darke, Shanks \& Broadbent, 1998). Documentary evidence often reflects issues of current interest or concern to both management and library staff, leading to a greater understanding of the learning culture.

Document analysis also provides valuable information on and understanding of past events of relevance to organisational transformation. Such documents allow researchers to make sense of this relevant history of events or experiences, including the original conceptualisation of the change, its implementation and possible contextual factors influencing the building of a learning culture, allowing researchers to make connections to the contemporary context.

Document analysis was used in two stages. In advance of the fieldwork publiclyavailable documentary evidence was sought from the library websites to give background information on the organisational context of the case studies. Evidence obtained at this stage included the historical background of the libraries, administrative information, including their functional areas and reporting structure, which allowed the researchers to become familiar with the cases. During fieldwork, document analysis was undertaken of a series of internal documents produced by and used within the libraries. The purpose of the research project was clarified with the library directors before requesting documentary evidence which could 
contribute to the study. The evidence obtained at this stage included library policies and strategies, annual reports, quality assurance reports, relevant projects and activities, and other administrative documents.

\section{Semi-structured interviews}

Interviews are one of the most important sources for case study research as they provide opportunities for reconstructing events which cannot be accomplished through other methods (Cunningham, 1993). The reconstruction can be formed by asking interviewees to think back over how a certain series of events unfolded in relation to the current situation (Bryman, 2012), such as a series of events or problems occurring following the adoption of the learning organisation concept in university libraries. Interviews should reveal the development and evolution of the concept over time, in addition to attempts to solve any problems which may have arisen during the organisational transformation.

Semi-structured interviews were conducted to investigate the experiences of university librarians and obtain their opinions, feelings, and attitudes towards the concept, the implementation process, and the problems faced. As the study entailed the investigation of multiple case libraries in which background, context and situation may differ, semi-structured interviews were the most appropriate method. The questions could not be rigidly prespecified; rather they needed to be adjusted to the specific situation of each library (Pickard, 2013). The interviews were conducted predominantly with the library directors as the implementation of the process in Thailand had been initiated top-down by senior 
management. It was the library executives who planned and shaped the organisational transformation through executing policy and strategies and creating strategic-aligned culture. In certain of the case libraries, the informal discussions were held with other staff, such as heads of departments, heads of the knowledge management committee, heads of the quality assurance committee, and the policy and planning analysts, amongst others. This additional method helped clarify library practices but was not a core part of the research methodology and was not included in the final report. An interview guide was prepared to ensure that important topics would be covered and investigated under the limitation of time and resources as well as to ensure cross-case comparability of the data derived from different case libraries.

\section{Direct observation}

One major limitation of the two methods discussed thus far is their inability to illuminate non-language factors such as a learning culture, working condition, staff behaviour, and social relationships within the organisations (Holliday, 2002). Observation is seen as a useful method in this context as it allows for the occurrence of certain types of these non-language factors to be observed (Gorman \& Clayton, 2005).

Direct observation was made throughout the fieldwork in order not to affect or interrupt daily work processes of the library staff. The researcher was external to the organisations and made aware of potential limitations on access. Observation could not be standardised formally; decisions on what to observe could not be made beforehand as 
organisations differed greatly in what they allowed outsiders to see. Furthermore, there is a tendency for staff to work in the way that they expect the researcher wants to see to impress the researcher rather than to "tell it like it is" (Schein, 2010, p. 180). As a result, observation was employed less formally with the aim of producing corroborating evidence for the other two methods.

Aspects observed were limited to the physical settings (such as arrangement of spaces, buildings, and technologies) and relevant events and activities. Permission was given by the library directors to carry out observation. If the observation included observing staff behaviour, staff were informed in advance and given the opportunity to refuse to take part. Staff were assured that the observation would pose no individual risk as the analysis would focus on collective behaviour; any observational data of individual staff would be excluded from the report. An observation form was used to re cord information, including both descriptive and reflective aspects.

\section{Conducting the case study}

The research fieldwork took place during a five-month period in Thailand, from September 2014 to February 2015, including one pilot and six actual case libraries.

\section{A pilot case study}

A pilot case study is a small scale preliminary test of the proposed methodology carried out before a large scale case study. The purpose is to test the usability of the 
conceptual base and evaluate the feasibility of the research design. By trying them out on a sample case, the research design and its elements can be refined before conducting an actual case study (Hulley, Cummings, Browner, Grady \& Newman, 2007). Criteria for selecting a pilot case may differ from those of the actual cases, as the focus is less on content or responses, but more on the structure of the tools and techniques to be used in the actual case study (Yin, 2014). Selection of a pilot case study is thus less structured, focusing more on developing a prolonged relationship between the interviewees and the researchers, so that different phenomena can be observed from different angles, employing different approaches on a trial basis. It may also be based on convenience, geographic proximity, congeniality, and accessibility.

The pilot case study for the project was a single exploratory case conducted in an Open University library located in Bangkok. The library was selected as it had an active interest in and made efforts towards developing as a learning organisation. As evidenced in documents and the library website, knowledge management had been implemented and the library had won a prize for innovation and best practice in the field, thus displaying evidence of relevant phenomena and information for the trial. The case was also chosen based on congeniality and accessibility allowing the prolonged relationship to be established and different approaches of inquiry to be tried out. Pilot case study tasks and activities were: 
- Clarification of the research aims and methods with the library director

- Browsing internal documentary evidence kept in folders, including meeting minutes and self-assessment reports as well as electronic documents stored on the library intranet and website

- Accessing the university website to seek information on university policy and strategies for analysing strategic alignment

- Conducting informal observation throughout the period of fieldwork together with formal observation (the library director took the researcher to walk around the library and had informal discussion with heads of departments.)

- Conducting a semi-structured interview with the library director

- Revision and mapping of all collected data and information derived from the pilot case The pilot case study focused on providing detailed information about lessons learned in order to use such data to modify the research plan, procedures and data collection methods for application to the actual cases. Lessons learned were:

- The concepts of learning organisation and knowledge management in Thailand were closely aligned and overlapped as they were introduced in parallel, leading to potential confusion between the two concepts. This made the researcher aware of one critical issue which needed careful treatment during later interviews.

- QA systems were seen as vital to the successful establishment of learning organisations in Thai university libraries. Under the QA framework initiated by the two Governmental 
bodies, OPDC and OHEC, it is compulsory for libraries to embed practices relating to learning organisation, knowledge management, and human resource development into their QA systems, together with appropriate KPIs for annual evaluation.

- Key documents to be used in the document analysis of the six main cases were identified, including:

- university and library policy and strategic plans for analysing strategic alignment

- annual reports

- self-assessment reports (SAR)

- human resource development plans

- information about related projects, for example establishing library core-values

- knowledge management projects and activities for analysing the practices within the libraries.

- Questions in the previous version of the interview guide overlapped. Some questions were not important as answers could be derived during the stage of document analysis or could be sought from other similar questions. They were, therefore, deleted or merged with other questions to save the interviewees' time.

\section{Six actual cases}

The research processes employed in the six cases were similar to the pilot in that it took approximately two weeks per case for data collection. During the first week, document 
analysis and direct observation were conducted. Semi-structured interviews with library directors or representatives followed in the second week. Core tasks and activities identified from the pilot case were used as a protocol for the six actual cases. As the examination involved investigating organisational problems which are sensitive issues in Thai culture, the fieldwork began with a clarification of the research purpose and methods with the library directors. Data collection followed, with the revision and mapping of all collected data completing the process. Core tasks and activities were:

- Clarifying research aims and methods with the library directors

- Browsing documents kept in folders, library websites, the libraries' knowledge management websites, or the libraries' quality assurance websites (if any) to seek relevant evidence regarding the universities' and libraries' policy and strategies, annual reports, self-assessment reports (SAR), and documents in relation to human resource development and knowledge management projects

- Observing activities organised within the libraries such as knowledge management activities or book fair activities, with observation of the latter focusing on staff cooperation when organising and facilitating the events. In some cases, formal observation was used during which the library directors took the researcher to walk around the library or unaccompanied, informal observation 
- Browsing information systems such as intranets, e-document portals, knowledge management portals, knowledge management websites, library blogs, or other knowledge sharing platforms

- Conducting semi-structured interviews with library executives, including library directors, associate directors, or deputy directors

Revising and mapping all data and information collected together. All collected data were revised, combined, and linkages made to produce an overall picture of each case. The key documents obtained from all the case libraries were their strategic plans and self-assessment reports. As indicated earlier, semi-structured interviews were conducted mainly with the library directors. In some cases, the interviews were assigned to associate directors or deputy directors directly responsible for implementing relevant policies and practices. Observation was conducted informally, except in one case where the library directors accompanied the researcher in an observation tour of the libraries. During the fieldwork, the researcher attempted to observe a range of aspects, including library events, staff team-working, technologies used in the library, division of workspace, and distribution of documents. Data sources obtained from each case are summarised in Table 1. 


\begin{tabular}{|c|c|c|c|c|c|c|}
\hline Data collection methods & $\begin{array}{c}\text { Library } \\
\text { A }\end{array}$ & $\begin{array}{c}\text { Library } \\
\text { B }\end{array}$ & $\begin{array}{c}\text { Library } \\
\text { C }\end{array}$ & $\begin{array}{c}\text { Library } \\
\text { D }\end{array}$ & $\begin{array}{c}\text { Library } \\
\text { E }\end{array}$ & $\begin{array}{c}\text { Library } \\
\text { F }\end{array}$ \\
\hline Document analysis (Types) & 7 & 6 & 9 & 8 & 7 & 5 \\
\hline University policy and strategies & $\bullet$ & $\bullet$ & $\bullet$ & & & $\bullet$ \\
\hline Library's background & - & - & - & $\bullet$ & - & - \\
\hline Library's strategic plans & 0 & - & $\bullet$ & 0 & - & ? \\
\hline Library's annual reports & $\bullet$ & $\bullet$ & $\bullet$ & $\bullet$ & $\bullet$ & \\
\hline Library's QA/SAR reports & $\bullet$ & $\bullet$ & $\bullet$ & - & $\bullet$ & $\bullet$ \\
\hline $\begin{array}{l}\text { Details of relevant projects and } \\
\text { activities }\end{array}$ & $\bullet$ & & & $\bullet$ & $\bullet$ & - \\
\hline $\begin{array}{l}\text { Examples of evaluation reports } \\
\text { of relevant projects and } \\
\text { activities }\end{array}$ & $\bullet$ & & $\bullet$ & & $\bullet$ & \\
\hline Others & & & & & & \\
\hline $\begin{array}{l}\text { Best practices captured from } \\
\text { KM activities }\end{array}$ & & & • & $\bullet$ & & \\
\hline Library journals / newsletters & & & $\bullet$ & $\bullet$ & & \\
\hline Meeting minutes & & $\bullet$ & & & & \\
\hline $\begin{array}{l}\text { The library director self- } \\
\text { reflection report }\end{array}$ & & & • & & & \\
\hline HRD plan & & & & $\bullet$ & & \\
\hline Research policy & & & & & $\bullet$ & \\
\hline
\end{tabular}




\begin{tabular}{|c|c|c|c|c|c|c|}
\hline $\begin{array}{l}\text { Semi-structured interview } \\
\text { (person) }\end{array}$ & 3 & 2 & 3 & 3 & 3 & 2 \\
\hline Library director & • & 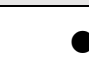 & - & Informal & $\bullet$ & $\bullet$ \\
\hline \multicolumn{7}{|l|}{ Others } \\
\hline Formal & & & & $\begin{array}{l}\text { Associate } \\
\text { Director }\end{array}$ & $\begin{array}{l}\text { Deputy } \\
\text { Director / } \\
\text { Head of } \\
\text { the } \\
\text { Planning } \\
\text { and Policy } \\
\text { Analyst }\end{array}$ & \\
\hline Informal & $\begin{array}{l}\text { Head of } \\
\text { QA /KM } \\
\text { committee }\end{array}$ & Staff & \begin{tabular}{|l|} 
Head of KM \\
committee / \\
The former \\
Deputy \\
Director
\end{tabular} & Staff & & Staff \\
\hline Observation (approx. hours) & 4 & - & Iade throughout the fieldv & ork period & 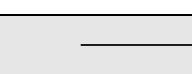 & 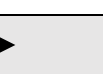 \\
\hline Library's events & $\bullet$ & 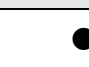 & $\bullet$ & & $\bullet$ & $\bullet$ \\
\hline Staff working in team & $\bullet$ & 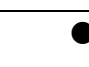 & $\bullet$ & $\bullet$ & $\bullet$ & $\bullet$ \\
\hline $\begin{array}{l}\text { Technologies used in the } \\
\text { library }\end{array}$ & $\bullet$ & $\bullet$ & $\bullet$ & $\bullet$ & $\bullet$ & $\bullet$ \\
\hline Division of workspace & $\bullet$ & 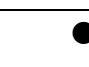 & $\bullet$ & $\bullet$ & $\bullet$ & $\bullet$ \\
\hline Distribution of documents & $\bullet$ & 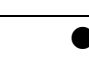 & $\bullet$ & $\bullet$ & $\bullet$ & $\bullet$ \\
\hline
\end{tabular}

Table 1: The data sources from each case 
Case study data analysis divided into two stages. Preliminary analysis was conducted in parallel with data collection. The researcher checked the collected data, summarised the major emerging issues, and identified aspects needing to be followed up. After completing data collection for each case, the formal data analysis started. Field notes, including document analysis and observation forms were summarised as well as transcribing recorded interviews. The researcher employed an inductive approach using thematic analysis involving the process of coding or reducing the data into meaningful ideas (Guest, MacQueen, \& Namey, 2012), reading and rereading the data, identifying key ideas or themes. The research findings were then presented thematically using the themes identified in the process of thematic analysis as an outline.

\section{Reflection and conclusion}

Overall, the adoption of an interpretivist lens and qualitative case study approach proved to be an appropriate research methodology, given the stated purpose of the research to achieve an understanding of the process of organisational transformation required of university libraries in becoming learning organisations. The investigation involved making sense of the establishment of the learning organisation, their management practices, and the extent to which such practices are compliant with and support the learning organisation.

Three qualitative data collection methods were employed, including document analysis, semi-structured interviews, and observation. The methods complement each other and produced an in-depth understanding of the topic. The methods also helped to capture the 
three M aspects of Garvin's framework which illuminated the development of the study. Analysis of the policy documents provided an understanding of the Meaning and Management aspects i.e. how libraries planned and implemented the learning organisation strategy through the execution of library policies and management practices. Interviews with the library directors clarified experiences, including their opinions and feelings towards the development of the concept. Observation helped interpret the workplace environment, spacing, and staff behaviour and explain how the concept worked in practice. All collected data were combined to provide an understanding of the extent to which Thai university libraries qualified as learning organisations. One major outcome of the study was the development of a unique model for investigating university libraries as learning organisations, incorporating both Garvin's three Ms and CSFs as key attributes (Limwichitr, 2016; Limwichitr, Broady-Preston \& Ellis, 2016).

The study developed a contextual approach to investigating learning organisations, to suit the Thai context and culture where the implementation of a LO framework was initiated via a top down approach, from Governmental policy through to the universities and their libraries. This contextual approach could, in turn, aid our understanding of the specific characteristics of its implementation in Thai university libraries as well as identifying defects. Although the approach proposed here is contingent, it could also be adapted and applied to other university libraries, for example libraries in neighbouring countries where contextual conditions are similar to the case libraries represented in the study. The interpretative 
approach could also be used to identify a number of relevant factors such as (1) how the organisational structure affects a learning culture; $(2)$ the role of the leader in developing a learning organisation; (3) the need to establish clear policies and strategies together with measurement and evaluation systems to understand why the university libraries are not successful in transforming themselves into learning organisations, the problems they face and the major blockages to organisational transformation.

As with all such studies, there are some limitations with regard to the transferability of the research methods for future studies. Firstly, as the study was conducted with public and autonomous university libraries, the research methods, including some research protocols may need modifications before applying these to other research settings.

Although the learning organisation concept emphasises involving library staff at all levels, interview data were collected solely from library executives as traditionally, policy execution in Thai university libraries is imposed top-down by management. It was library executives who actually planned and shaped the transformation into learning organisations. However, this places potential limits in achieving the wider range of perspectives obtainable from a cross-section of staff, including developing a broader understanding of the topic. Further studies may consider including staff at all levels to supplement the data derived solely from library executives.

It should also be noted that decision to select either a single case study or a multiple case study design is essentially governed by a trade-off between breadth and depth. 
Conducting an in-depth single case study may offer the opportunity to derive a greater understanding of the phenomenon, whilst conversely a multiple case study design allows for greater breadth in the investigation at the expense of less depth. Applying research methodology to a single case library will potentially provide an enhanced richer understanding of the current situation in a particular library in more detail.

Last but not least, a period of data collection is regarded as a significant element in terms of validity and rigour in gaining an in-depth understanding and insight into a learning organisation. The longer the period of time during which the research takes place, the more an in-depth understanding can be created. Conducting a longitudinal case study may allow organisational transformation to be tracked more effectively and enable researchers to gain an in-depth understanding of a learning culture.

\section{References}

Bordeianu, S., \& Lubas, R. (2013). Interaction between departments: strategies for improving interdepartmental collaboration through communication. In Blessinger, K., \& Hrycaj, P. (Eds.), Workplace culture in academic libraries: The early 21st Century (pp.219-229). Oxford: Chandos.

Bratton, J. (2010). Work and organizational behaviour. $2^{\text {nd }}$ Ed. Basingstoke: Palgrave Macmillan. 
Bryman, A. (2012). Social research methods. $4^{\text {th }}$ Ed. Oxford: Oxford University Press.

Creaser, C., \& Spezi, V. (2012). Working together: Evolving value for academic libraries. Retrieved from: https://libraryvalue.files.wordpress.com/ 2012/06/ndm-5709-lisufinal-report_web.pdf

Creswell, J. W. (2013). Qualitative inquiry and research design: Choosing among five approaches. $3^{\text {rd }}$ Ed. London: Sage.

Cunningham, J. B. (1993). Action research and organizational development. London: Praeger.

Darke, P., Shanks, G., \& Broadbent, M. (1998). Successfully completing case study research: combining rigour, relevance and pragmatism. Information Systems Journal, 8(4), 273-28

Eberle, T. S., \& Maeder, C. (2011). Organizational Ethnography. In Silverman, D. (Ed.) Qualitative Research. (pp. 53-73). $3^{\text {rd }}$ Ed.. London: Sage.

Farquhar, J. D. (2012). Case study research for business. London: Sage.

Figueroa, L. A., \& González, A. B. (2006). Management of knowledge, information and organizational learning in university libraries. Libri, 56, 180-190. 
Flyvbjerg, B. (2006). Five misunderstandings about case-study research. Qualitative Inquiry, 12(2), 219-245.

Fowler, R. (1998). The university library as learning organization for innovation: An exploratory study. College \& Research Libraries, 59(3), 220-231.

Fri, G. W., \& Bi, H. (2013). The evolution of educational reform in Thailand: The Thai educational paradox, Journal of Educational Administration, 51(3), 290-319.

Garavan, T. (1997). The learning organization: A review and evaluation. The Learning Organization, 4(1), 18-29.

Garvin, D. A. (1993). Building a learning organisation. Harvard Business Review, 71(4), 78-91.

Giesecke, J., \& McNeil, B. (2004). Transitioning to the learning organization. Library Trends, 53(1), 54-67.

Gorman, G. E., \& Clayton, P. (2005). Qualitative research for the information professional a practical handbook. London: Facet.

Grieves, J. (2008). Why we should abandon the idea of the learning organization. The Learning Organization, 15(6), 463-473.

Guest, G., MacQueen, K. M., \& Namey, E. E. (2012). Applied thematic analysis. London: SAGE. 
Hitt, W. D. (1995). The learning organization: Some reflections on organizational renewal. Employee Counselling Today, 8(7), 16-25.

Holliday, A. (2002). Doing and writing qualitative research. London: Sage. .

Hulley, S. B., Cummings, S. R., Browner, W. S., Grady, D. G., \& Newman, T. B. (2007). Designing clinical research. $4^{\text {th }}$ Ed. Philadelphia: Lippincott Williams and Wilkins.

Jain, P., \& Mutula, P. (2008). Libraries as learning organisations: Implications for knowledge management. Library Hi Tech News, 8, 10-14.

Jones, A. (1994). Creating a learning organization. PhD dissertation, University of Warwick.

Kitt, C. M. (2008). Towards being a learning organisation - a business excellence approach. $\mathrm{PhD}$ dissertation, Durham University.

Limwichitr, S.; Broady-Preston, J., \& Ellis, D. (2015). A discussion of problems in implementing organisational cultural change. Library Review, 64(6/7), 480-488.

Limwichitr, S., Broady-Preston, J.; \& Ellis, D. (2016). Developing a model for investigating academic libraries as learning organisations. Proceedings of the IDIMC 2016: Exploring our digital shadow: from data to intelligence (pp. 54-65). 12-13 January 2016, Loughborough University. Retrieved from https://idimc.files.wordpress.com/2016/02/2016-idimc-proceedings.pdf 
Limwichitr, S. (2016). Developing a model for investigating university libraries as learning organisations. PhD dissertation, Aberystwyth University.

Madge, O. (2013). Academic libraries as learning organisations: A Romanian perspective. Paper presented at IFLA World Library and Information Congress. $79^{\text {th }}$ IFLA General Conference and Assembly, 17-23 August 2013, Singapore.

Marquardt, M. J. (2011). Building the learning organization: Achieving strategic advantage through a commitment to learning. London: Nicholas Brealey.

Marsick, V. J., \& Watkins, K. E. (2003). Demonstrating the value of an organization's learning culture: The dimensions of the learning organization questionnaire. Advances in Developing Human Resources, 5(2), 132- 151.

Martin, J. (2013). Organisational culture and administrative change: A case study at a metropolitan academic library. In Blessinger, K. \& Hrycaj, P. (Eds.) Workplace culture in academic libraries: The early 21st Century (pp. 39-56).Oxford: Chandos,

Mavodza, J. (2010). Knowledge management practices and the role of an academic library in a changing information environment: The case of the metropolitan college of New York. PhD dissertation, University of South Africa.

McHugh, D., Groves, D., \& Alker, A. (1998). Managing learning: What do we learn from a learning organisation? The Learning Organization, 5(5), 209-220. 
Michael, T .S .C., \& Higgins,S. (2002). NTU Nanyang Technological University Library as a learning organisation. Libri, 52, 169-182.

Mueller, J. (2012). The interactive relationship of corporate culture and knowledge management: A review. Review of Managerial Science, 6(2), 183-201.

Mullins, L. J. \& Christy, G. (2016). Management and organisational behaviour. $11^{\text {st }}$ Ed. New York: Pearson Education.

Mumford, A. (1995). The learning organization in review. Industrial and Commercial Training, 27 (1), 9-16.

OPDC. (2003). Royal Decree on Criteria and Procedures for Good Governance. Retrieved from http://www.opdc.go.th/english/content.php?url=view\&cat_id=3

Örtenblad, A. (2015). Towards increased relevance: Context-adapted models of the learning organization. The Learning Organization, 22(3), 163-181.

Parding, K., \& Abrahamsson, L. (2010) Learning gaps in a learning organization: Professionals' values versus management values. Journal of Workplace Learning, 22(5), 292-305.

Patton, M. Q. (2015). Qualitative research and evaluation methods. ${ }^{\text {th }}$ Ed. London: Sage.

Pedler, M., Burgoyne, J., \& Boydell, T. (1997). The Learning Company: A strategy for sustainable development. London: McGraw-Hill. 
Pickard, A. J. (2013). Research methods in information. $2^{\text {nd }}$ Ed. London: Facet.

Portfelt, I. S. (2006). The University: A Learning Organization? - An Illuminative Review Based on System Theory. PhD dissertation, Karlstad University.

Ritchie, J. (2003). The applications of qualitative methods to social research. In Ritchie, J. \& Lewis, J. (Eds.) Qualitative research practice: A guide for social Science students and researchers (pp.27-46). London: Sage.

Rowley, J. (1997). The library as a learning organization,.Library Management, 18(2), 88-91.

Schein, E. H. (2010). Organizational culture and leadership. $4^{\text {th }}$ Ed. San Francisco: Jossey-Bass.

Senge, P. M. (1995). The fifth discipline: The art and practice of the learning organization. London: Random House.

Shakir, M. (2002). The selection of case studies: Strategies and their applications to IS implementation cases studies. Research Letters in the Information and Mathematical Sciences, 3, 191-198.

Su, D. (2009). Review of ecology-based strategy change theories. International Journal of Business and Management, 4(11), 69-72.

Sudharatna, Y. (2004). Towards a stage model of learning organisation development. $\mathrm{PhD}$ dissertation, the University of Adelaide. 
Temple, J. (2006). Developing and implementing a knowledge management strategy in a multicultural engineering design environment. $\mathrm{PhD}$ dissertation, Cranfield University.

Worrell, D. (1995). The learning organization: Management theory for the information age or new age fad? Journal of Academic Librarianship, 21(5), 351-357.

Yin, R. K. (2014). Case study research: Design and methods. $5^{\text {th }}$ Ed. London: Sage.

\section{Acknowledgements}

This study could not have been completed without the cooperation of all the participating libraries. I am grateful to the directors for giving permission to carry out the fieldwork and to all the research participants who took part in both the pilot and main study.

\section{Open access and copyright}

Library and Information Research is an open access journal. A freely available copy of this paper may be downloaded from the journal's website: http://ww.lirgjournal.org.uk

Copyright and associated moral rights in works published in Library and Information Research are retained by the author(s) but this paper may be used freely, with proper attribution, in educational and other non-commercial settings. 